\title{
PRINCÍPIO DA IMPARCIALIDADE DO JUIZ: CONFLITOS COM OS PROCESSOS MENTAIS HUMANOS
}

\author{
PRINCIPLE OF JUDGE IMPARTIALITY: CONFLICT WITH HUMAN MENTAL \\ PROCESSES
}

\section{PRINCIPIO DE LA IMPARCIALIDAD DEL JUEZ: CONFLICTOS CON LOS PROCESOS MENTALES HUMANOS}

\begin{abstract}
ANa Flavia de Andrade Nogueira CAStilho
https: / /orcid.org/0000-0002-6716-2018 / http://lattes.cnpq.br/3391572909352332 / afancmch@gmail.com

Mestre em Teoria do Estado e do Direito no UNIVEM/Marília SP. Pós Graduada em Direito Tributário na LEGALE São Paulo SP. Pós-graduanda em Psicologia Jurídica na USC/Bauru SP. Advogada. Marília, SP, Brasil
\end{abstract}

Ricardo Pinha Alonso

https://orcid.org/0000-0002-4535-4721 / http://lattes.cnpq.br/6127172734397904 / ripial1@gmail.com

Doutor em Direito do Estado pela Pontifícia Universidade Católica de São Paulo. Professor titular - Faculdades Integradas de Ourinhos e do Centro Universitário Eurípides de Marília. Coordenador da graduação e pós-graduação das Faculdades Integradas de Ourinhos. Marília, SP, Brasil.

NELSON FINOTTI SILVA

https://orcid.org/0000-0001-8502-5562 / http://lattes.cnpq.br/8190248086562267 / nfinotti1@gmail.com

Procurador do Estado de São Paulo. Doutor em Direito Processual Civil pela Pontifícia Universidade Católica de São Paulo. É professor titular da Faculdade de Filosofia Ciências e Letras de Catanduva do curso de Pós-Graduação "latu sensu", professor do Pós-Graduação "stricto sensu" da Fundação de Ensino Eurípedes Soares da Rocha (UNIVEM - Centro Universitário Eurípedes de Marilia. Marília, SP, Brasil.

\section{RESUMO}

A pesquisa tem por objetivo analisar as decisões judiciais sob a perspectiva da psicologia cognitiva. O problema se assenta sobre o questionamento da (in) existência da imparcialidade e da neutralidade do juiz quando das análises das provas e tomadas de decisões. Utilizou-se do método de pesquisa hipotético-dedutivo com abordagem qualitativa e objetivos exploratórios. 0 trabalho abordou os processos cognitivos mentais humanos e sua importância nas atividades no cotidiano, além de explicar teorias que contribuem para desvendar o desenvolvimento do conhecimento humano e a formação de suas ações. A ênfase do trabalho está no conflito existente entre as funções mentais (sensação, percepção, pensamento, linguagem, emoções e memórias) e a essencialidade da imparcialidade do juiz na fase de instrução e de julgamento processual. Nas considerações finais, aponta-se que a neutralidade humana em uma decisão judicial não é possível e que a imparcialidade existe em diferentes proporcionalidades, aprimorando a ideia de sentença justa por meio de um juiz instrutor e um juiz julgador.

Palavras-chave: decisão; princípio da imparcialidade; provas; processos cognitivos; psicologia cognitiva.

\section{ABSTRACT}

The research aims to analyze judicial decisions from the perspective of cognitive psychology. The problem is based on the questioning of the (in) existence of impartiality and the neutrality of the judge when analyzing the evidence and making decisions. The hypothetical-deductive research method with a qualitative approach and exploratory objectives has used. The work dealt with the human mental cognitive processes and their importance in daily activities, besides explaining theories that contribute to unveil the development of human knowledge and the formation of their actions. 
The emphasis of the work lies in the conflict between the mental functions (sensation, perception, thought, language, emotions and memories) and the essentiality of the impartiality of the judge in the stage of instruction and procedural judgment. In the final considerations, it is pointed out that human neutrality in a judicial decision is not possible and that impartiality exists in different proportions, enhancing the idea of a just sentence through an instructor judge and a judging judge.

Keywords: decisions; principle of impartiality; evidence; cognitive processes; cognitive psychology.

\section{RESUMEN}

La investigación tiene por objetivo analizar las decisiones judiciales bajo la perspectiva de la psicología cognitiva. El problema se basa en el cuestionamiento de la existencia de la imparcialidad y de la neutralidad del juez en los análisis de las pruebas y tomas de decisiones. Se utilizó el método de investigación hipotético-deductivo con abordaje cualitativo y objetivos exploratorios. El trabajo abordó los procesos cognitivos mentales humanos y su importancia en las actividades en el cotidiano, además de explicar teorías que contribuyen a desvelar el desarrollo del conocimiento humano y la formación de sus acciones. El énfasis del trabajo está en el conflicto existente entre las funciones mentales (sensación, percepción, pensamiento, lenguaje, emociones y memorias) y la esencialidad de la imparcialidad del juez en la fase de instrucción y de juicio procesal. En las consideraciones finales, se señala que la neutralidad humana en una decisión judicial no es posible y que la imparcialidad existe en diferentes proporciones, mejorando la idea de sentencia justa por medio de un juez instructor y un juez juzgador.

Palabras clave: decisión; principio de imparcialidad; evidencias; procesos cognitivos; psicología cognitiva.

\section{SUMÁRIO}

INTRODUÇAO; 1PROCESSOS COGNITIVOS; 2 A IMPARCIALIDADE DO JUIZ; 3 CONFLITOS: IMPARCIALIDADE E PROCESSOS MENTAIS; 3.10 desafio de julgar; CONSIDERAÇÕES FINAIS; REFERÊNCIAS.

\section{INTRODUÇÃO}

As conexões entre as ciências têm sido de grande valia para compreender o comportamento humano e suas ações dentro de um grupo social comum. Exemplos desta interligação entre ciências humanas que refletem colheitas de bons frutos estão na psicologia cognitiva, psiquiatria e Direito.

Não são raras as discussões que percorrem os subjetivismos de um julgamento, de seu processo de conhecimento e das instruções probatórias. Sob esse prisma aborda-se neste trabalho os seguintes questionamentos: é possível um magistrado ser absolutamente imparcial ou neutro para analisar provas e para julgar uma lide, ou seja, é uma verdade o princípio da imparcialidade?

As decisões e as ações humanas são influenciadas por diversas funções mentais. Tais funções mentais constituem-se pela sensação, percepção, memória, emoção, pensamento e linguagem. Os estudos da psicologia cognitiva podem contribuir para devida interpretação e compreensão do comportamento humano e os reflexos sociais destes, uma vez que seus objetos de estudos são os processos cognitivos - funções que conduzem uma personalidade humana.

Parte o estudo das acepções dos processos mentais, das teorias que fundamentam esses processos, como a teoria Freudiana, a teoria do desenvolvimento humano de Jean Piaget, o 
ISSN 1981-3694

(DOI): $10.5902 / 1981369427841$

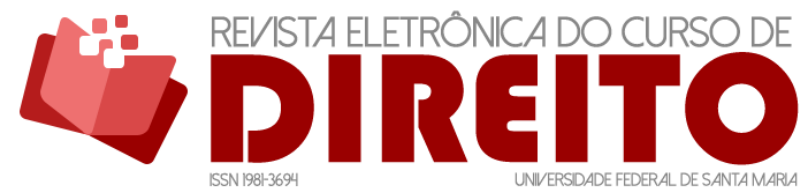

PRINCÍPIO DA IMPARCIALIDADE DO JUIZ: CONFLITOS COM OS PROCESSOS MENTAIS HUMANOS

ana Flavia de Andrade Nogueira Castilho RICARDO PINHA ALONSO NELSON FINOTTI SILVA

raciocínio humano segundo Daniel Kahneman e a teoria do complexo de Jung. Necessariamente, esse aporte teórico variado é para sustentar que o ser humano não pode ser inteiramente razão.

Sem grande complexidade, trata a pesquisa sobre a suposta imparcialidade do juiz, os conflitos existentes entre os graus de parcialidade e os processos mentais inerentes da pessoa, avaliando a personalidade do indivíduo e suas prováveis reações diante da necessidade de decidir, além de enfatizar os desafios de julgar do magistrado.

Neste contexto, a pesquisa se realiza pelo método de pesquisa hipotético-dedutivo, por meio da abordagem qualitativa e com objetivos exploratórios.

\section{PROCESSOS COGNITIVOS}

As ciências cogitam questionamentos, às vezes, sem respostas ou que se enchem de hipóteses duvidosas sob a perspectiva da racionalidade, no que diz respeito às atividades humanas em um meio social, como no campo da educação, da psiquiatria, da criminalidade e em qualquer ato que depende da ação do ser humano que se exteriorizam provenientes de um processo de cognição.

Em especial, as ciências humanas, como a sociologia, a psicopedagogia, as ciências jurídicas e a psiquiatria, necessitam mergulhar em um terreno complexo e sofisticado - o planeta psíquico - para encontrar a compreensão de muitas condutas humanas ${ }^{1}$ que projetam no meio social algo positivo ou negativo.

A pessoa humana não é dotada inteiramente de racionalidade. A psicologia vem ao longo dos anos demonstrando que inexiste a neutralidade mental, ou seja, a isenção emocional em um organismo. Augusto Cury ${ }^{2}$, um psiquiatra psicanalista, analisou profundamente o “EU”, estudando por mais de 30 anos seus pacientes, investigando suas emoções, seus atos e reflexos em um meio social. Diante do entendimento de como poderia funcionar a mente humana, estudou seus reflexos à sociedade, como por exemplo, a importância da sensação, da percepção e da interpretação humana para com o próximo. Para ele, a interpretação é uma armadilha em que todos falham. Isto porque interpreta-se tudo e todos segundo o "EU" que se conhece - nós mesmos.

\footnotetext{
1 CURY, Augusto. O funcionamento da mente: uma jornada para o mais incrível universo. São Paulo, Cultrix, 2016, p. 11.

2 Ibidem.
} 
ISSN 1981-3694

(DOI): $10.5902 / 1981369427841$

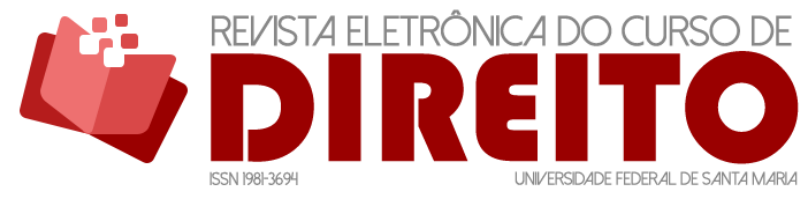

PRINCÍPIO DA IMPARCIALIDADE DO JUIZ: CONFLITOS COM OS PROCESSOS MENTAIS HUMANOS

ana Flavia de Andrade Nogueira Castilho RICARDO PINHA ALONSO NELSON FINOTTI SILVA

Nesta perspectiva adotada por Cury, a chance de se obter interpretações equivocadas e a existência de atrocidades oriundas das ações humanas é consideravelmente grande ${ }^{3}$. Cury ${ }^{4}$ afirma que "há muitos profissionais cometendo erros graves; determinando e apontando a direção; condenando; dando diagnósticos de maneira mágica [...] dentro de seu sistema intelectual e interpretativo". Existe a necessidade de democratizar as ideias, ou seja, jamais uma percepção ou uma interpretação será unicamente correta.

Este parâmetro de Cury não salta de pensamentos aleatórios. É necessário compreender que a análise dos processos mentais foi feita por nomes como Freud, Piaget, Yung e Kahneman. Esses estudiosos desenvolveram teorias diferentes, mas com fins semelhantes - compreender o funcionamento da mente e seus universos.

Sigmund Freud, criador da psicanálise, concluiu que somos acorrentados em um mundo reprimido pelo próprio "EU” chamado de "inconsciente"- terreno que armazena as frustrações, o imoral, as fantasias, as decepções, fatos dolorosos e principalmente os traumas da infância ${ }^{5}$. Esse inconsciente é despertado e atualizado em vários momentos da vida, de maneira que se faz uso deles em ações diárias, porém não se percebe ou não se aceita.

A teoria de Freud estabelece uma conexão entre o inconsciente e a formação da personalidade durante a infância, no qual se carrega por toda a vida. Jean Piaget não trabalha o inconsciente, mas algo que se conecta com este - a formação da cognição. Piaget ${ }^{6}$ realizou vários estudos que levassem ao conhecimento da formação da inteligência humana. Para apurar suas teorias, Piaget acompanhou crianças desde o nascimento, suas primeiras sensações, percepções e assimilações de fatos exteriores verificando também as construções biológicas.

Para Piaget ${ }^{7}$ há uma associação entre a razão e a organização das funções psicológica (pensamento, sentimento, sensação ou intuição) que se é necessária para o nascimento da inteligência. Desta forma, interpreta-se que há a construção da personalidade por meio das experiências vividas, armazenam-se estas no inconsciente e, da mesma forma com as experiências de sensação, percepção e assimilação das experiências físicas edificam-se o conhecimento.

${ }^{3}$ CURY, Augusto. O funcionamento da mente: uma jornada para o mais incrível universo. São Paulo, Cultrix, 2016, p. 83.

${ }^{4}$ Ibidem., p. 83-84.

${ }^{5}$ FREUD, Sigmund. Primeiras publicações psicanalíticas. Volume III. 1893-1899.

${ }^{6}$ PIAGET, Jean. 0 nascimento da inteligência na criança. $10^{\mathrm{a}}$ edição - Portugal/Porto, Editora Movilivro, 1986.

${ }^{7}$ Ibidem. p. 15. 
ISSN 1981-3694

(DOI): $10.5902 / 1981369427841$

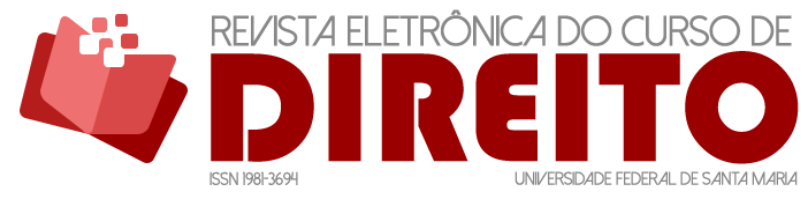

PRINCÍPIO DA IMPARCIALIDADE DO JUIZ: CONFLITOS COM OS PROCESSOS MENTAIS HUMANOS

ana Flavia de Andrade Nogueira Castilho RICARDO PINHA ALONSO NELSON FINOTTI SILVA

0 raciocínio de que existe um inconsciente que contribui para a formação da personalidade se estende à teoria do complexo de Carl Gustav Jung ${ }^{8}$, na qual situações exteriores desencadeiam processos psíquicos que consistem na concentração e atualização de determinados conteúdos guardados na memória. Ou seja, por exemplo, uma palavra ouvida ou uma imagem observada resgata do inconsciente as lembranças positivas ou negativas influenciando nas condutas realizadas diariamente.

Entrementes, passa-se a entender o que são os processos cognitivos psíquicos, sua relevância no cotidiano e porque envolvê-los com o direito.

A psicologia cognitiva teve sua origem na teoria do conhecimento desenvolvida por Jean Piaget, na qual tem por objeto de estudo o comportamento mental humano, exteriorizado por intermédio de diversos mecanismos, dentre eles, a memória, o raciocínio, a intuição, o pensamento e a linguagem. Segundo Tobler ${ }^{9}$ essa exteriorização pode ocorrer de modo consciente ou inconsciente, ou seja, o cérebro ao receber uma informação externa, capta o seu conteúdo, e por meio de fatores neurológicos, elabora uma resposta para a situação.

Para que o cérebro receba a informação exterior, ele conhece os primeiros dois processos - a sensação e a percepção. Após, a memória e o consciente são despertadas ou o inconsciente sem que se perceba, depende da informação recebida e se houve alterações da sensação e percepção pelas emoções. A sequência dessa sistemática é a formação do pensamento e da linguagem.

As funções mentais se constituem em uma espécie de programação por meio do qual as pessoas desenvolvem imagens mentais de si mesmo e do mundo físico, interpretam os estímulos que recebem, elaboram a realidade psíquica e emitem comportamentos ${ }^{10}$.

As funções mentais são apresentadas como sensação, percepção, atenção, memória, pensamento, linguagem e emoção.

A sensação, de acordo com Fiorelli e Mangini ${ }^{11}$ são informações do mundo exterior ou do próprio organismo que chegam ao cérebro, permitindo que o cérebro forme uma imagem mental

8 JUNG, Carl Gustav. A natureza da psique. Petrópolis: Editora Vozes, 2000, p. 18.

9 TOBLER, Gisele Caroline. Decisão Penal: as contribuições da psicologia cognitiva. Dissertação. Universidade Federal de Santa Catarina, 2015, p. 68.

10 FIORELLI, José Osmir. MANGINI, Cathya Ragazzoni. Psicologia Jurídica. $6^{a}$ edição. São Paulo: Atlas, 2015, p.11.

11 Ibidem. p. 11. 
ISSN 1981-3694

(DOI): $10.5902 / 1981369427841$

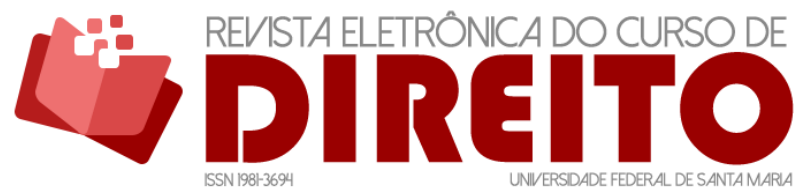

PRINCÍPIO DA IMPARCIALIDADE DO JUIZ: CONFLITOS COM OS PROCESSOS MENTAIS HUMANOS

ana Flavia de Andrade Nogueira Castilho RICARDO PINHA ALONSO NELSON FINOTTI SILVA

correspondente a elas. A percepção é a etapa seguinte da sensação, realiza a interpretação da imagem mental resultante da sensação ${ }^{12}$.

A memória é a faculdade de reproduzir conteúdo inconsciente, de forma que as informações são recebidas pelos sentidos (olfato, tato, olhos, paladar, audição), que despertam a atenção e ativa a memória. Isso possibilita o reconhecimento de lugares por onde já passou ou músicas que lembram algum momento da vida.

Importante salientar que quando a memória é acionada a emoção afeta a sensação (informações recebidas do mundo exterior), alterando a imagem mental formada e, consequentemente, terá alterações na percepção, ou seja, na interpretação da imagem mental processada. Isso faz com que ocorra o não reconhecimento de um lugar, por exemplo.

A emoção é um complexo estado de sentimentos, com componentes somáticos, psíquicos e comportamentais relacionados ao afeto e ao humor ${ }^{13}$. Elas podem ser positivas, como a felicidade, a alegria, o amor, ou negativas, como a raiva, a tristeza, a surpresa, o medo, a inveja, a paixão e a repugnância.

A sequência dos processos mentais é estabelecida pelo pensamento e pela linguagem. São funções mentais associadas. 0 pensamento é a atividade mental associada com o processamento, a compreensão e a comunicação de informações. A linguagem condiciona o registro dos acontecimentos na memória, porque as práticas, as percepções, o conhecimento, transformam-se quando são exteriorizados (falados).

Jean Piaget ${ }^{14}$ afirma que as pessoas desenvolvem a capacidade de pensar passando por vários estágios desde o nascimento: primeiro a descoberta do mundo e de si mesmo (sensóriomotor), depois na fase pré-operacional, inicia-se a solução de problema; e entre o $7^{\circ}$ e $10^{\circ}$ ano de idade a criança passa pela fase do operatório-concreto, no qual começa a distinguir a aparência da realidade - muda a percepção sobre o mundo, objetos e pessoas.

Nesta perspectiva teórica, será de grande valia o conhecimento da teoria de Daniel Kahneman. 0 psicólogo assimila a economia com a ciência cognitiva, isto é, estuda a influência das funções cognitivas nas tomadas de decisões pessoais e no mundo dos negócios empresariais.

12 FIORELLI, José Osmir. MANGINI, Cathya Ragazzoni. Psicologia Jurídica. $6^{a}$ edição. São Paulo: Atlas, 2015, p. 11.

${ }^{13}$ KAPLAN, Harold. SADOCK, Benjamim. Compêndio de psiquiatria. 6. ed. Porto Alegre: Artes médicas, 1993, p. 230.

${ }^{14}$ PIAGET, Jean. 0 nascimento da inteligência na criança. $10^{\mathrm{a}}$ edição - Portugal/Porto, Editora Movilivro, 1986. 
ISSN 1981-3694

(DOI): $10.5902 / 1981369427841$

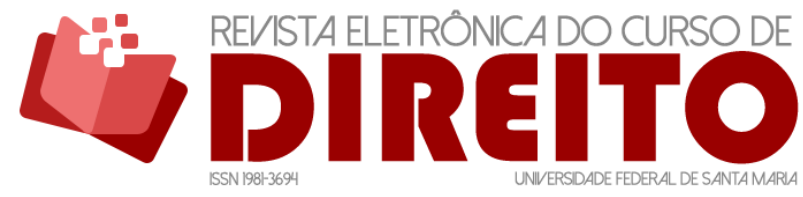

PRINCÍPIO DA IMPARCIALIDADE DO JUIZ: CONFLITOS COM OS PROCESSOS MENTAIS HUMANOS

ana Flavia de Andrade Nogueira Castilho RICARDO PINHA ALONSO NELSON FINOTTI SILVA

Kahneman ${ }^{15}$ defende que a mente humana possui dois sistemas mentais fictícios: o S1 e o S2. O S1 seria o pensamento rápido e superficial e o S2 o pensamento lento que se utiliza para solucionar problemas complexos ou manter a concentração mental na execução de alguma ação. Todos os processos mentais supracitados são ativados quando trabalham os sistemas mencionados por Kahneman.

Para Kahneman ${ }^{16}$, o cérebro é limitado quanto à assimilação das informações e processamento que levem as decisões e julgamentos complexos. Prefere-se utilizar o S1 por não demandar esforços de raciocínios, isto porque há um gasto grande de energia no sistema nervoso para desenvolver coisas complexas. A mente tende a ficar cansada e segue o caminho do menor esforço. O Sistema S1 além de rápido e automático também tende a aceitar uma informação inicial como verdadeira. É o imediatismo. Logo, por exemplo, o primeiro pensamento, às vezes, é de que não gostamos de determinada pessoa sem conhecê-la. Criam-se prejulgamentos e é confortável tê-los como verdadeiros a desenvolver uma teoria diferente para tomar uma decisão diferente ou criar novas acepções.

\section{A IMPARCIALIDADE DO JUIZ}

A palavra imparcialidade dentro do processo estabelece um raciocínio de indiferença as partes e as provas, no qual não há uma colaboração do juiz com uma parte ou outra no que diz respeito à procedência dos pedidos ou não, além de tratar de um pressuposto de validade processual. A imparcialidade do juiz é uma garantia para as partes e à medida que o Estado reservou para si o exercício da função jurisdicional, este tem o dever de agir com imparcialidade na solução de conflitos que the são submetidos ${ }^{17}$.

Não são raras as vezes que a imparcialidade é confundida com a neutralidade. Existe uma diferença entre essas duas terminologias. A neutralidade se fecha a qualquer grau de subjetividade e a imparcialidade é o distanciamento do juiz da subjetividade. A decisão dentro de um processo não se deveria se coadunar com a subjetividade ou com a moral, dada a interpretação de justiça no âmbito jurídico não se confundir com a justiça que concentra em cada ser humano ou grupos de pessoas distintas.

\footnotetext{
${ }^{15}$ KAHNEMAN, Daniel. Rápido e devagar: duas formas de pensar. Tradução Kássio de Arantes Leite. Rio de Janeiro, Objetiva, 2012.

${ }^{16}$ Ibidem.

17 CINTRA, Antônio Carlos de Araújo; GRINOVER, Ada Pellegrini; DINAMARCO, Cândido Rangel. Teoria geral do processo. 11. ed. São Paulo: Malheros Editores, 1995, p. 52.
} 
ISSN 1981-3694

(DOI): $10.5902 / 1981369427841$

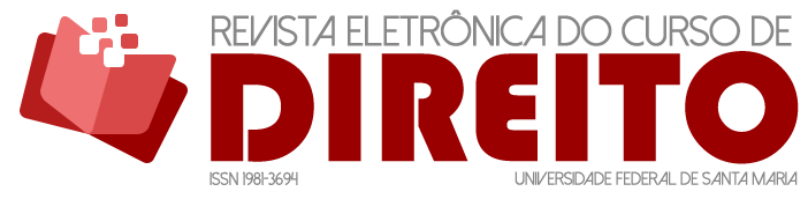

PRINCÍPIO DA IMPARCIALIDADE DO JUIZ: CONFLITOS COM OS PROCESSOS MENTAIS HUMANOS

ana Flavia de Andrade Nogueira Castilho RICARDO PINHA ALONSO NELSON FINOTTI SILVA

Esse distanciamento entre o Direito, a moral e a justiça é fruto do positivismo jurídico. Não se sustenta uma crítica ao positivismo, mas observações válidas para entender-se que determinadas ideias embora existam como válidas e necessárias, não permeiam o universo humano. Kelsen ${ }^{18}$ sustentou que "quando uma teoria do Direito positivo se propõe distinguir Direito e moral em geral e Direito e Justiça em particular, para não os confundir entre si, ela volta-se contra a concepção tradicional”. Leia-se, que a concepção tradicional seja o já mencionado - o que é moral e justiça para cada ser humano não se confunde com a justiça no Direito.

O juiz tem um grau de imparcialidade, assim como todo ser humano, mas não são máquinas para serem neutros. Pamplona ${ }^{19}$ adverte ser impossível para qualquer pessoa conseguir abstrair os "seus traumas, complexos, paixões [...] no desempenho de suas atividades cotidianas, eis que a manifestação de sentimentos é um dos aspectos fundamentais que diferencia a própria condição de ente humano em relação ao frio "raciocínio" das máquinas computadorizadas".

\section{CONFLITOS: IMPARCIALIDADE E PROCESSOS MENTAIS}

Invariavelmente, Lênio Streck se preocupa com a postura dos juízes brasileiros, que segundo o jurista, eles se pautam em decidirem conforme suas convicções pessoais e profissionais. Streck ignora as emoções da pessoa humana e a posição desta antes do cargo ocupado. Em uma de suas oportunidades midiáticas observa que existem apenas dois tipos de juízes, um dogmático, voluntarista, autoritário e o outro cheio de "boas intenções”20.

Em uma tentativa de compreender os apontamentos de Streck, pode-se observar o que ensina Tobler ${ }^{21}$, quando disserta que o Direito se amolda a duas teorias distintas, sendo uma a teoria formalista, no qual o direito se apresenta como uma ciência determinada, imutável, fixa e insuscetível de qualquer subjetividade por parte do julgador, de maneira que a decisão está “diretamente ligada ao fato concreto e sua correspondente formalidade legal, ao juiz é suficiente apenas seguir aquilo que a lei dispõe; aqui a subjetividade é justificada pela

\footnotetext{
18 KELSEN, Hans. Teoria pura do direito. Tradução de João Baptista Machado. 7. ed. São Paulo: Martins Fontes, 2006, p. 75.

19 PAMPLONA FILHO, Rodolfo. O mito da neutralidade do juiz como elemento de seu papel social.2001. Disponível em:<http://jus.com.br/revista/texto/2052>. Acesso 23 de junho de 2017.

${ }^{20}$ STRECK, Lenio Luiz. Dilema de dois juízes diante do fim do Livre Convencimento do NCPC. 2015. Disponível em: <http://www.conjur.com.br/2015-mar-19/senso-incomum-dilema-dois-juizes-diante-fimlivre-convencimento-ncpc>. Acesso em: 23 de junho de 2017.

${ }^{21}$ TOBLER, Gisele Caroline. Decisão Penal: As contribuições da psicologia cognitiva. Dissertação. Universidade Federal de Santa Catarina, 2014.
} 
ISSN 1981-3694

(DOI): $10.5902 / 1981369427841$

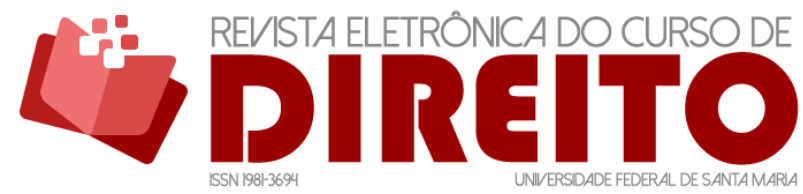

PRINCÍPIO DA IMPARCIALIDADE DO JUIZ: CONFLITOS COM OS PROCESSOS MENTAIS HUMANOS

ana FlaVia de Andrade Nogueira CAstilho RICARDO PINHA ALONSO NELSON FINOTTI SILVA

uniformidade do preceito legal. Nesse sentido, a decisão é essencialmente fruto das normas”. E a outra, é a teoria realista, que ao contrário da anterior, interpreta "o direito como uma ciência indeterminada, passível de interpretações, que vai além do próprio ordenamento jurídico e cuja decisão está alicerçada por vezes em fatores estranhos ao direito"22. Segundo essa teoria a decisão está ligada aos fatos concretos indeterminados, isto é, não existe necessariamente uma relação direta com as normas jurídicas ${ }^{23}$.

O que aparenta é que a ideia de Streck quanto aos dois modelos de juízes, já vem trabalhada nestas teorias citadas por Tobler ${ }^{24}$. Porém, as dúvidas que movem muitas discussões sobre as decisões dos juízes encontram colaborações para possíveis respostas e compreensões dentro da psicologia cognitiva. Não se quer defender o livre convencimento do juiz por meio de suas convicções pessoais sem as devidas fundamentações, mas apenas reafirmar que juízes não são máquinas e muito menos um fantoche comandado pelo Estado.

Ao ser humano não foi dada apenas a racionalidade. 0 indivíduo tem como principal característica uma personalidade que se constrói desde o ventre materno para o longo da vida. Parte da personalidade se forma por meio do inconsciente e interfere nas decisões do dia a dia.

A personalidade pode ser conceituada como o total relativismo estável e previsível das emoções e comportamentos que caracteriza a pessoa na vida cotidiana, desde que livre de quaisquer patologias psíquicas ${ }^{25}$. Nas palavras de Fiorelli e Mangini ${ }^{26}$, personalidade se conceitua como "a condição estável e duradoura dos comportamentos da pessoa, embora não permanente".

Os comportamentos típicos, estáveis, persistentes que determinam um padrão por meio do qual o indivíduo se comporta no meio social, no trabalho e no âmbito familiar, são denominadas de características da personalidade e as manifestações dessas características processam e formam uma imagem mental nos observadores, dos comportamentos mais esperados em cada tipo de circunstância, ou seja, as atitudes de uma pessoa são totalmente previsíveis ao observar as características da sua personalidade ${ }^{27}$.

22 TOBLER, Gisele Caroline. Decisão Penal: As contribuições da psicologia cognitiva. Dissertação. Universidade Federal de Santa Catarina, 2014.

23 Ibidem.

24 Ibidem.

25 KAPLAN, Harold; SADOCK, Benjamim. Compêndio de psiquiatria. 6. ed. Porto Alegre: Artes médicas, 1993, p. 556.

${ }^{26}$ FIORELLI, José Osmir; MANGINI, Cathya Ragazzoni. Psicologia Jurídica. 6. ed. São Paulo: Atlas, 2015, p. 100.

27 Ibidem. 
ISSN 1981-3694

(DOI): $10.5902 / 1981369427841$

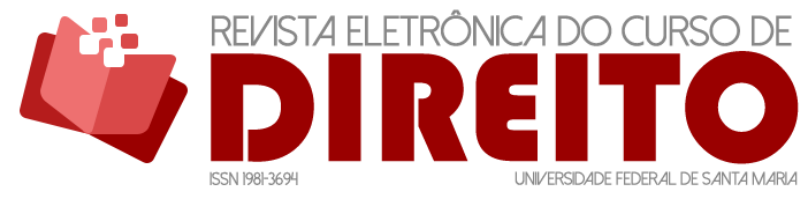

PRINCÍPIO DA IMPARCIALIDADE DO JUIZ: CONFLITOS COM OS PROCESSOS MENTAIS HUMANOS

ana Flavia de Andrade Nogueira Castilho RICARDO PINHA ALONSO NELSON FINOTTI SILVA

O magistrado possui uma personalidade própria. A personalidade do juiz pode explicar diversos comportamentos, tais como dificuldade em condenar, atitudes agressivas, falta de paciência, constante posição defensiva, medo, humor instável, ira, indiferença, arrogância, timidez, temores, angústias, frustrações, competitividade, dificuldade em lidar com críticas, insegurança, dentre outros ${ }^{28}$.

Refletir que existe a possibilidade de o indivíduo ter uma personalidade adversa do comum, como uma personalidade depressiva, paranoide, maníaca, esquizofrênica, fóbica, narcisista ou histérica, gera um conflito ainda maior com a imparcialidade do juiz, pois pode haver um desequilíbrio emocional grande em pessoas dotadas de uma dessas personalidades que fogem ao padrão de normalidade. Insta lembrar que não existe uma personalidade considerada “normal”. Segundo Fiorelli e Mangini ${ }^{29}$, todas apresentam aspectos negativos e positivos, sendo cada ser humano único em sua estrutura psicológica e orgânica.

0 psiquiatra psicanalista David Zimerman ${ }^{30}$, ressalta que cada um tem um juízo crítico, por sua vez, "este é uma das funções mais nobres do ego, e se constitui como sendo uma das vigas mestras na vida das inter-relações pessoais e na tomada de decisões judicantes", de modo que essa capacidade crítica ganha maior relevância na atividade cotidiana de um juiz.

Entrementes, interpreta Zimerman ${ }^{31}$, que se um indivíduo é portador de juízos prévios, se ele tem "pré-conceitos" radicais e rígidos, ele perde a isenção para julgar, porque a sua visão objetiva ficará contaminada pela subjetiva. Importante lembrar que, conforme o estudado no item anterior, os processos mentais e suas funções tornam o ser humano incapaz de ser totalmente isento de suas concepções estabelecidas na construção de seus conhecimentos ou que estejam na sua memória de uso contínuo ou periférica (inconsciente), ou seja, sempre haverá algum juízo prévio.

Zimerman $^{32}$ considera cada personalidade e coaduna com o ato de decidir do juiz. 0 autor faz os seguintes apontamentos: se a personalidade do juiz for depressiva, apresenta dificuldades para condenar. Se a personalidade for paranoide, manter-se-á constantemente em defensiva, apresentando agressividade. Se a personalidade for maníaca, ele apresentará humor instável e, diante de qualquer frustração, poderá se irar. Se a personalidade for esquizoide, ele

\footnotetext{
${ }^{28}$ AMBRÓSIO, Graziella. Psicologia do juiz. Ver. Direito Econ. E Socioambiental, Curitiba, v 3, n 2, p. 491 503. Julh/dez 2012, p. 495.

${ }^{29}$ FIORELLI, José Osmir; MANGINI, Cathya Ragazzoni. Psicologia Jurídica. 6. ed. São Paulo: Atlas, 2015, p. 100.

${ }^{30}$ ZIMERMAN, D. A influência dos fatores psicológicos inconscientes na decisão jurisdicional: a crise do magistrado. THEMIS - Revista da Escola Superior da Magistratura do Estado do Ceará, 2011, p. 131.

31 lbidem. p. 132.

32 Ibidem. p. 135-138.
} 
ISSN 1981-3694

(DOI): 10.5902/1981369427841

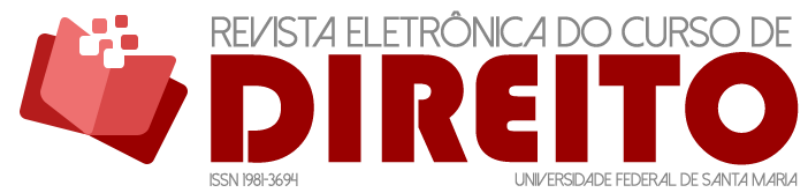

PRINCÍPIO DA IMPARCIALIDADE DO JUIZ: CONFLITOS COM OS PROCESSOS MENTAIS HUMANOS

ana Flavia de Andrade Nogueira Castilho RICARDO PINHA ALONSO NELSON FINOTTI SILVA

terá dificuldades de relacionamento, em razão da timidez e do medo de ser rejeitado. Se a personalidade for fóbica, ele terá dificuldades em se comprometer com uma delicada decisão judicial. Se a personalidade tiver traços obsessivos, ele se tornará um julgador implacável e radical. Se a personalidade for histérica, ele terá baixa capacidade de tolerar frustrações. Se a personalidade for psicopática, ele não terá consideração pelos demais, pois antes de servir aos outros, ele serve-se destes. E se a personalidade do juiz for narcisista, ele não tolerará qualquer crítica que desmereça sua propriedade da verdade e da razão, bem como terá a tendência de se cercar de pessoas que o admirem e o aplaudam.

Além das indesejadas personalidades supracitadas, Zimerman ${ }^{33}$ adverte que poderá o magistrado "se tornar um péssimo inimigo, capaz de vinganças mesquinhas ou de manifestar indiferença hostil para quem tiver opiniões e iniciativas próprias, diferentes das dele" quando há uma combinação destas personalidades.

Diante deste contexto criado nesta pesquisa, importa considerar que é inevitável a interferência psicológica do juiz no ato de julgar, pois, além de conhecimentos teóricos, o juiz detém as funções mentais ativas permanentemente e é observador de todos os envolvidos no litígio. Todos estes conjuntos de informações interferem em sua sentença. Ter essa visão de como funciona a mente e como exteriorizam a personalidade poderá capacitar o magistrado a compreender os conteúdos intrapsíquicos e os efeitos dos conscientes e inconscientes na sua decisão. Em uma sentença, tem-se muito mais que a simples aplicação das normas jurídicas ao caso concreto, têm-se vidas, pessoas que carregam histórias de vidas independentes e crenças diferentes, pessoas que intimidam de formas distintas, que conquistam por afinidades, que remetem ao passado, que despertam emoções e que retiram a racionalidade pela expressão da sua dor, sensibilidade, sofrimento e injustiças. Não se tem máquinas trabalhando no judiciário para ignorar a magnitude do ser humano.

A percepção do juiz deve alcançar os fenômenos mentais que se manifestam em seu organismo, como também os processos psíquicos das partes, dos advogados e das testemunhas. Lembra Ambrósio ${ }^{34}$ que o juiz é um ser humano e, como tal, vulnerável a diversos sentimentos que afetam sua decisão e, seria ingenuidade pensar que o magistrado tem a capacidade de se despir de todas as suas crenças, valores e referências sociais para proferir uma sentença. Assim,

33 ZIMERMAN, D. A influência dos fatores psicológicos inconscientes na decisão jurisdicional: a crise do magistrado. THEMIS - Revista da Escola Superior da Magistratura do Estado do Ceará, 2011, p. 138.

${ }^{34}$ AMBRÓSIO, Graziella. Psicologia do juiz. Ver. Direito Econ. E Socioambiental, Curitiba, v 3, $n^{\circ}$ 2, p. 491 503. Julh/dez 2012, p. 494. 
ISSN 1981-3694

(DOI): $10.5902 / 1981369427841$

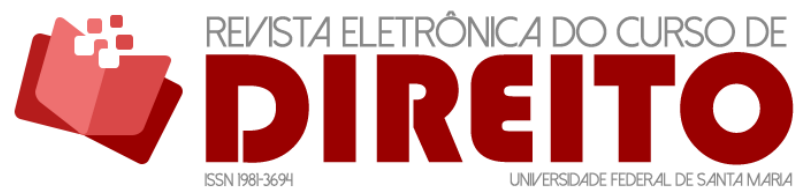

PRINCÍPIO DA IMPARCIALIDADE DO JUIZ: CONFLITOS COM OS PROCESSOS MENTAIS HUMANOS

ana Flavia de Andrade Nogueira Castilho RICARDO PINHA ALONSO NELSON FINOTTI SILVA

o juiz pode sentir medo, raiva, amor, compaixão, intolerância, repulsa, revolta, tristeza, prepotência, dentre outros, interpreta a autora.

A emoção é um processo mental que merece destaque nesta discussão. Isso porque ela altera a sensação e a percepção, que são os primeiros processos mentais que possibilitam o conhecimento do mundo físico e ativam as janelas da memória.

Ao trabalhar a relação do cérebro com as emoções humanas, o neurologista Antônio Rosa Damásio ${ }^{35}$, interpreta que a emoção delimita o campo da ação e conduz à razão, isto é, existe um equilíbrio entre a emoção e a razão. Damásio ${ }^{36}$ assevera que "mesmo sendo verdade que o aprendizado e a cultura alteram as expressões das emoções e thes conferem novos significados, as emoções são processos determinados biologicamente, e dependem de mecanismos cerebrais estabelecidos de modo inato".

Têm-se distorções conferidas pelo estado emocional até mesmo das informações lógicas, afirma Cury ${ }^{37}$. 0 estado emocional no momento do resgate da memória (exemplo: medo, felicidade, tristeza), o ambiente social, a capacidade de gerenciar perdas somadas ao metabolismo cerebral dado pela carga genética interferem na leitura da memória e nos pensamentos ${ }^{38}$.

Interpreta-se, que as experiências anteriores do juiz podem interferir na sentença. Isso explica, por exemplo, porque o magistrado involuntariamente tem afeição ou repulsa por pessoas comuns, como mulheres loiras, homens violentos, pais, mães, policiais, vítimas em geral, padres, pastores, médicos, professores, políticos, etc., fato que persevera 0 entendimento de que o "equilíbrio para o julgamento só é alcançado por meio do controle do mecanismo psicológico do juiz, que permite o reconhecimento e o direcionamento de tudo o que é captado pelos sentidos"39.

Facchini Neto $^{40}$ trabalha o tema ao abordar o viés da independência psicológica do magistrado, ou seja, da possibilidade de o magistrado desenvolver opiniões autônomas que não sejam aquelas decisões que se preocupam apenas em uniformizar a jurisprudência, mas sim ser

\footnotetext{
35 DAMÁSIO, Antônio Rosa. O erro de descartes. São Paulo: Campanha das letras, 1996.

36 Ibidem. p. 75.

${ }^{37}$ CURY, Augusto. O funcionamento da mente: uma jornada para o mais incrível universo. São Paulo, Cultrix, 2016, p. 93.

38 Ibidem.

${ }^{39}$ AMBRÓSIO, Graziella. Psicologia do juiz. Direito Econômico e Socioambiental. Curitiba, v 3, $\mathrm{n}^{\circ} 2, \mathrm{p}$. 491-503. Julh/dez 2012, p. 497.

40 FACCHINI NETO, Eugênio. O poder judiciário e sua independência: uma abordagem de direito comparado. Revista Jurídica Luso Brasileira - RJLB, Ano 1, 2015, $\mathrm{n}^{\circ}$ 3, páginas 509-511. Disponível em: <https://www.cidp.pt/publicacoes/revistas/rjlb/2015/3/2015_03_0499_0547.pdf>. Acesso em: 17 de junho de 2018.
} 
ISSN 1981-3694

(DOI): 10.5902/1981369427841

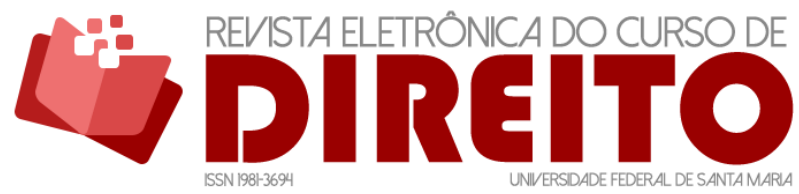

PRINCÍPIO DA IMPARCIALIDADE DO JUIZ: CONFLITOS COM OS PROCESSOS MENTAIS HUMANOS

ana Flavia de Andrade Nogueira Castilho RICARDO PINHA ALONSO NELSON FINOTTI SILVA

mais adequada ao caso concreto, conforme o ponto de vista jurídico do julgador. Tal apontamento pode ensejar a insegurança jurídica ao interpretar que a independência psicológica do magistrado pode direcionar para o posicionamento de primeiro decidir e depois fundamentar. Ora, se julgar é um ato de vontade seria ilusão negar aqui um certo grau de subjetivismo em uma decisão, como adverte Facchini, "que seria ingênuo desconhecer-se que o juiz pode estar vinculado a preconceitos próprios de sua origem social, de sua concepção política ou de sua visão do mundo; que em nenhum homem se pode eliminar um último resto de subjetivismo".

Neste contexto, sob a perspectiva do estudado, a ideia de um juiz instrutor e outro para realizar o julgamento dentro de um processo poderá se respaldar nos estudos da psicologia cognitiva. Como o pesquisado, não há valoração das provas e decisões sem fazer-se uso das emoções, do consciente e do inconsciente, ou seja, permeia o processo um grau de parcialidade independente do interesse do magistrado de beneficiar uma das partes. Assim, restaria prejudicado a normativa que instrui a identidade física do juiz, isto é, o mesmo juiz que realiza a instrução deve proferir a decisão. Porém a contaminação da sentença pelo subjetivismo seria menor se atuassem no processo juízes diferentes, uma vez que o juiz julgador não participaria da instrução probatória, decidindo segundo a lei e princípios gerais do direito.

\subsection{O Desafio de Julgar}

Os julgadores não são apenas os magistrados. Julgam os juízes, os jurados, os que acusam e os que defendem, julgam todos que opinam. E nestes entremeios todos trabalham seus julgamentos primeiro com a realidade dos relatos do que com os fatos, por meio de seus filtros sensoriais (visão, audição, tato, olfato, paladar) e cognitivos (sensação, percepção, emoção, memória, pensamento, linguagem), impregnados de valores e conceitos, experiências, expectativas e contexto da época ${ }^{41}$.

Dos julgadores formais (juízes) exigem-se conhecimentos técnicos, mas não se despreza o fato de que suas experiências de vida influenciam em suas decisões. Sob uma ótica de camuflagem, o novo código de processo civil textualizou essa realidade quando assentou no artigo 375 a seguinte redação: “o juiz aplicará as regras de experiência comum subministradas pela observação do que ordinariamente acontece e, ainda, as regras de experiência técnica, ressalvado, quanto a estas, o exame pericial".

Há quem visualize uma ideia de retrocesso do processo civil brasileiro no que se refere à produção de provas e sua valoração pelo magistrado, ao analisar as alterações feitas na redação

${ }^{41}$ FIORELLI, José Osmir; MANGINI, Cathya Ragazzoni. Psicologia Jurídica. 6. ed. São Paulo: Atlas, 2015, p. 175-176. 
ISSN 1981-3694

(DOI): $10.5902 / 1981369427841$

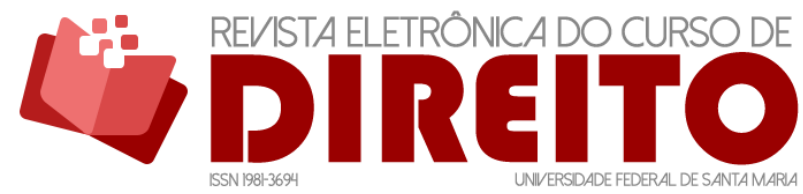

PRINCÍPIO DA IMPARCIALIDADE DO JUIZ: CONFLITOS COM OS PROCESSOS MENTAIS HUMANOS

ana Flavia de Andrade Nogueira Castilho RICARDO PINHA ALONSO NELSON FINOTTI SILVA

deste artigo, que antes se posicionava no artigo 335 do CPC/1973, que na íntegra aduzia: "em falta de normas jurídicas particulares, o juiz aplicará as regras de experiência comum subministradas pela observação do que ordinariamente acontece e ainda as regras da experiência técnica, ressalvado, quanto a esta, o exame pericial”.

Lênio Streck ${ }^{42}$ contesta e repudia a redação do artigo 375 do CPC/2015 supracitado, enfatizando que não se trata de uma análise de provas de forma objetiva e sim subjetiva, algo supostamente não aceito no âmbito jurídico. O que retrata um retrocesso, segundo Streck, é que no código de processo civil de 1973 se enfatizava que as regras da experiência comum, poderiam ser aplicadas na ausência de normas jurídicas específicas. 0 legislador retirou essa particularidade do texto do dispositivo, ensejando dúvidas sobre como se aplicará tais regras da experiência e o que seriam essas regras da experiência comum!?

0 juiz Napoleão Nunes Maia Filho ${ }^{43}$ do Tribunal Regional Federal da $5^{\circ}$ Região, leciona que a expressão regras da experiência comum veicula um conceito juridicamente indeterminado, que só adquire operacionalidade quando o juiz the der adequado conteúdo, por meio de atividade de preenchimento de seu significado, ou seja, não se tem determinada o que são regras da experiência comum, de modo que vai se concretizar no momento oportuno de acordo com o caso concreto.

O ser humano se nutre de suas experiências anteriores e do conhecimento que foi incorporado ao longo de sua existência e não apenas o conhecimento teórico, intelectuais, mas também as provenientes de outras fontes, como as dos duros embates da vida e das suas adversidades ${ }^{44}$.

Vencidas tais considerações, insta ressaltar que as experiências de um indivíduo são sistematizadas por lembranças que entrelaçam entre a memória atual e o inconsciente, além de moldados por emoções logo após a percepção sensorial, fato que enseja subjetividade na avaliação e na valoração das provas. Reconhecer e controlar as próprias emoções é o ideal. Outros fatores, como o cansaço físico, mecanismos psicológicos de defesa (o esquecimento, por

\footnotetext{
42 STRECK, Lênio Luiz. O NCPC e as esdrúxulas "regras de experiência": verdades ontológicas? 2015. Disponível em: < http://www.conjur.com.br/2015-abr-09/senso-incomum-ncpc-esdruxulas-regrasexperiencia-verdades-ontologicas >. Acesso em: 23 de junho de 2017.

43 MAIA FILHO, Napoleão Nunes. As regras da experiência comum na formação da convicção do juiz. Revista dialética de direito processual civil, $n^{\circ} 17,2004$, p. 67.

${ }^{44}$ Ibidem. p. 59.
} 
ISSN 1981-3694

(DOI): $10.5902 / 1981369427841$

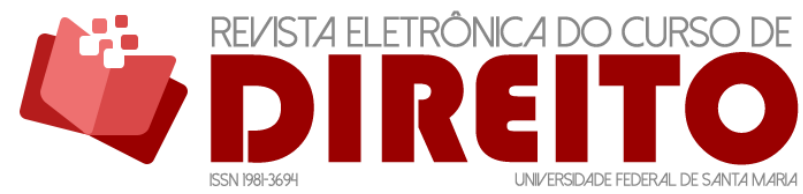

PRINCÍPIO DA IMPARCIALIDADE DO JUIZ: CONFLITOS COM OS PROCESSOS MENTAIS HUMANOS

ana Flavia de Andrade Nogueira Castilho RICARDO PINHA ALONSO NELSON FINOTTI SILVA

exemplo), pensamentos automáticos e crenças arraigadas poderão desviar a atenção que merecia determinadas atividades, como ouvir diversas testemunhas, por exemplo ${ }^{45}$.

Sob esta perspectiva advertem Fiorelli e Mangini ${ }^{46}$, que deixar-se dominar pela emoção quer dizer que haverá um comprometimento da percepção, atenção, pensamento e memória, isto significa abrir espaço para enganos de raciocínio (conclusões inadequadas), esquemas rígidos de pensamentos e preconceitos. Assim, o julgamento absoluto é um mito. Ou seja, "todo julgar é relativo e realiza-se dentro de um contexto, para o qual contribuem não apenas os elementos de origem social, mas também os conteúdos intrapsíquicos de cada participante" ${ }^{47}$.

\section{CONCLUSÃO}

O presente trabalho foi realizado com intuito de examinar as teorias e os objetos de estudos da psicologia cognitiva com o propósito de compreender a impossibilidade de imparcialidade integral e a neutralidade do magistrado. Este atingiu o objetivo esperado, mas sem a pretensão de conclusões taxativas, sendo apenas realizados alguns apontamentos sobre a temática.

A primeira análise consistiu em trazer um conhecimento sobre algumas das teorias que alimentam a psicologia e alguns vieses da psiquiatria, que são elas a teoria do inconsciente de Freud, a teoria do conhecimento de Piaget, a teoria do pensamento e tomada de decisão de Daniel Kahneman e a teoria do complexo de Jung. Todas apenas superficialmente citada, diante da complexidade de suas hermenêuticas.

Entrementes, observou-se que a decisão rápida é fruto de preconcepções que possuem compreensões pré-estabelecidas e o cérebro raramente vai mudar sua interpretação sobre determinado fato. Ao analisar uma prova documental ou ouvir uma testemunha, o ser humano dotado de conhecimento jurídico e também ciente do seu papel de julgador conforme a lei, não estará neutro e nem imparcial à situação fática, haja vista, que as emoções afetam a sensação e a percepção, o que existe é um domínio do certo e do errado, assim como um domínio das emoções.

Se há uma minuciosa avaliação, interpretação e compreensão, ou seja, as provas estão sendo analisadas de forma consciente, tenta-se afastar a vontade humana, suas crenças e com o sentimento de que a decisão deverá ser justa de acordo com os fatos, acredita-se que a

\footnotetext{
45 FIORELLI, José Osmir; MANGINI, Cathya Ragazzoni. Psicologia Jurídica. 6. ed. São Paulo: Atlas, 2015, p. 178.

46 Ibidem. 180.

${ }^{47}$ Ibidem. p. 182
} 
ISSN 1981-3694

(DOI): $10.5902 / 1981369427841$

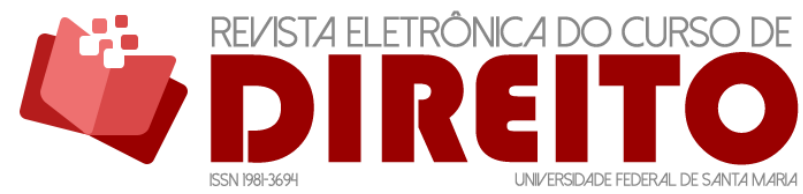

PRINCÍPIO DA IMPARCIALIDADE DO JUIZ: CONFLITOS COM OS PROCESSOS MENTAIS HUMANOS

ana Flavia de Andrade Nogueira Castilho RICARDO PINHA ALONSO NELSON FINOTTI SILVA

porcentagem de imparcialidade será maior, diante da capacidade de maior domínio da própria personalidade. Quanto à neutralidade, esta não será possível, a não ser aos portadores de patologia psíquica como a psicopatia.

Julgar é um desafio para o indivíduo que formalmente tem que resolver um litígio e ao mesmo tempo dar uma resposta para a sociedade a respeito dos males que a corrompem, sendo tais males, na maioria das vezes, provenientes da criminalidade.

Procede a possibilidade de figurar no processo um juiz instrutor e outro julgador. Assim porque assenta a psicologia cognitiva que o ser humano não tem autonomia para desprender-se de suas preconcepções, de suas emoções, da memória atual e do inconsciente, ou seja, não tem possibilidade de ser imparcial. Embora há muito tempo aceita-se o princípio da identidade física do juiz como algo salutar para o processo, interpreta-se com estes estudos que o ideal seria afastar tal instrumentalidade. Talvez, já se tenha dado o primeiro passo para futuramente considerar essa possibilidade no ordenamento jurídico brasileiro ao ter o novo código de processo civil suprimido tal regra de seu texto.

Neste contexto, não há uma solução mágica para estabelecer um julgamento totalmente imparcial e justo. 0 que se espera é um conhecimento do magistrado do universo psíquico humano e admitir este que o ser humano é falho e refém de sua personalidade, e ainda, essa compreensão e fato poderia ser em algum momento aceito pelos estudos jurídicos, reformando conceitos velhos de ser o Direito uma ciência autônoma intocável. Pode-se interpretar isso talvez nas palavras de Paulo Ferreira da Cunha ao poetizar: "quem só sabe o direito... nem o direito sabe”.

\section{REFERÊNCIAS}

AMBRÓSIO, Graziella. Psicologia do juiz. Direito Econ. E Socioambiental, Curitiba, v 3, $n^{\circ} 2, p$. 491-503. Julh/dez 2012. Disponível em: < https://periodicos.pucpr.br/index.php/direitoeconomico/article/viewFile/6230/6152>. Acesso em: 17 de junho de 2018.

CINTRA, Antônio Carlos de Araújo; GRINOVER, Ada Pellegrini. DINAMARCO, Cândido Rangel. Teoria geral do processo. $11^{a}$ ed. São Paulo: Malheros Editores, 1995.

CURY, Augusto. O funcionamento da mente: uma jornada para o mais incrível universo. São Paulo: Cultrix, 2016.

DAMÁSIO, Antônio Rosa. O erro de descartes. São Paulo: Campanha das letras, 1996.

DAMÁSIO, Antônio Rosa. 0 mistério da consciência. São Paulo: Campanha da Letras, 2000.

FACCHINI NETO, Eugênio. O poder judiciário e sua independência: uma abordagem de direito comparado. Revista Jurídica Luso Brasileira - RJLB, Ano 1, 2015, n³ 3, páginas 499-547. 
ISSN 1981-3694

(DOI): 10.5902/1981369427841

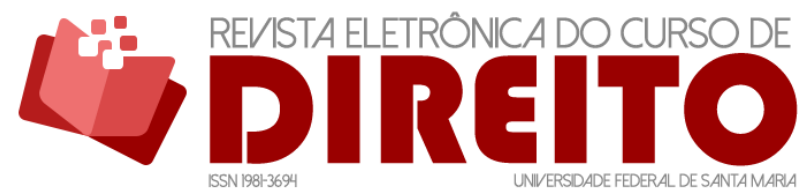

PRINCÍPIO DA IMPARCIALIDADE DO JUIZ: CONFLITOS COM OS PROCESSOS MENTAIS HUMANOS

Ana Flavia de Andrade Nogueira Castilho RICARDO PINHA ALONSO NELSON FINOTTI SILVA

Disponível em: https://www.cidp.pt/publicacoes/revistas/rjlb/2015/3/2015_03_0499_0547.pdf. Acesso em: 17 de junho de 2018.

FIORELLI, José Osmir; MANGINI, Cathya Ragazzoni. Psicologia Jurídica. 6. ed. São Paulo: Atlas, 2015.

FREUD, Sigmund. Primeiras publicações psicanalíticas. Volume III. 1893-1899. Disponível em:< http: / / www.psicanaliseflorianopolis.com/artigos/147-obras-completas-de-sigmund-freud.html >. Acesso em: 03 mai. 2016.

JUNG, Carl Gustav. A natureza da psique. Petrópolis: Editora Vozes, 2000.

KAHNEMAN, Daniel. Rápido e devagar: duas formas de pensar. Tradução Kássio de Arantes Leite. Rio de Janeiro: Objetiva, 2012.

KAPLAN, Harold. SADOCK, Benjamim. Compêndio de psiquiatria. 6. ed. Porto Alegre: Artes médicas, 1993.

KELSEN, Hans. Teoria pura do direito. Tradução de João Baptista Machado. 7. ed. São Paulo: Martins Fontes, 2006

MAIA FILHO, Napoleão Nunes. As regras da experiência comum na formação da convicção do juiz. Revista dialética de direito processual civil, $\mathrm{n}^{\circ}$ 17, 2004, p. 59-70. Disponível em: < https://www5.trf5.jus.br/documento/?arquivo=As+regras+da+experi\%EAncia+comum+na+forma\% E7\%E3o+da+convic\%E7\%E3o+do+juiz.pdf\&tipo=p10>. Acesso em: 17 de junho de 2018.

PAMPLONA FILHO, Rodolfo. 0 mito da neutralidade do juiz como elemento de seu papel social. Disponível em: <http://jus.com.br/revista/texto/2052>. Acesso em: 23 jun. 2017.

PIAGET, Jean. 0 nascimento da inteligência na criança. 10. ed. Portugal/Porto: Editora Movilivro, 1971.

STRECK, Lênio Luiz. Dilema de dois juízes diante do fim do Livre Convencimento do NCPC. Disponível em: <http://www.conjur.com.br/2015-mar-19/senso-incomum-dilema-dois-juizesdiante-fim-livre-convencimento-ncpc>. Acesso em: 23 jun. 2017.

STRECK, Lênio Luiz. O NCPC e as esdrúxulas "regras de experiência": verdades ontológicas? Disponível em: http://www.conjur.com.br/2015-abr-09/senso-incomum-ncpc-esdruxulas-regrasexperiencia-verdades-ontologicas. Acesso em: 10 dez. 2017.

TOBLER, Gisele Caroline. Decisão Penal: As contribuições da psicologia cognitiva. Dissertação. Universidade Federal de Santa Catarina, 2015.

ZIMERMAN, D. A influência dos fatores psicológicos inconscientes na decisão jurisdicional: a crise do magistrado. Disponível em:

<http://bdjur.stj.jus.br/jspui/bitstream/2011/18217/A_Influ\%C3\%AAncia_dos_Fatores_Psicol\%C 3\%B3gicos.pdf>. Acesso em: 23 jun. 2017.

Recebido em: 23.06.2017 / Revisões requeridas em: 07.06.2018 / Aprovado em: 09.07.2018 / Publicado em: 30.08.2018.

\section{COMO FAZER A REFERÊNCIA DO ARTIGO (ABNT):}

CASTILHO, Ana Flavia de Andrade Nogueira, ALONSO, Ricardo Pinha; SILVA, Nelson Finotti;. Princípio da imparcialidade do juiz: conflitos com os processos mentais humanos. Revista Eletrônica do Curso de Direito da UFSM, Santa Maria, RS, v. 13, n. 2, p. 489-505, ago. 2018. ISSN 1981-3694. Disponível em: < https: //periodicos.ufsm.br/revistadireito/article/view/27841 >. Acesso em: dia mês. ano. doi: http://dx.doi.org/10.5902/1981369427841 . 